\title{
Study of the Partial Shading Effect on the Performance of Silicon PV Panels String
}

\author{
${ }^{1}$ Shaima K. Abdulridha, ${ }^{1}$ Saad A. Tuma, ${ }^{* 1}$ Omar A. Abdulrazzaq \\ ${ }^{1}$ Renewable Energy and Environment Research Center/ Corporation of Research and Industrial Development/ Ministry \\ of Industry and Minerals/ Baghdad-Iraq
}

\section{Article information}

Article history:

Received: March, 27, 2021

Accepted: April, 17, 2021

Available online: April, 26, 2021

Keywords:

PV Module

Shading

Photovoltaic

Power loss

Correspondence:

Omar A. Abdulrazzaq

omarsatar2003@gmail.com

\begin{abstract}
In this work, the effect of maintenance bridges partial shading on the performance of the Renewable Energy and Environment Research Center (REERC) PV system was thoroughly investigated, in order to estimate the power loss amount in the PV system due to the maintenance bridges. The study was performed on one panel, then projected on the whole system (540 panels). Partial shade area of the bridges was measured monthly for 9 months ( 3 months were missing because of the pandemic). The utilized panel in this study is a $2 \mathrm{~m}^{2}$ area panel with 96 solar cells connected in series. Measurements were carried out at three different daytimes for each month (8:30AM, 10:00AM, and 12:00PM). The results showed that loss is occurred in current and power only, where voltage showed less influence with partial shade. The results of the panel were projected to the whole system to estimate the loss of the total REERC system (540 PV panel). The designed power of the system is $155 \mathrm{~kW}$. The actual rated power was $78 \mathrm{~kW}$ at noon in March 9, 2020. This is a drop of 50\% of the power. This huge drop is a combined effect for both partial shade and ambient temperature.
\end{abstract}

DOI: 10.53293/jasn.2021.11022, Department of Applied Science, University of Technology

This is an open access article under the CC BY 4.0 license.

\section{Introduction}

Solar energy is an alternative source of renewable energy and a clean teck for the environment; it is a solution to the humankind environmental problems nowadays. The sunshine hours vary from country to country. Highest sunshine hours located in region between the tropical of Cancer and the tropical of Capricorn with sunshine hours more than 4000 [1]. This is the region between latitudes $23.5^{\circ}$ and $-23.5^{\circ}$. Iraq is located on the latitude $33^{\circ}$, which is close enough to the Cancer-Capricorn tropical region with sunshine hours of 3000-3600 [2]. This makes Iraq a feasible location for large-scale PV systems.

Photovoltaic panels are affected by temperature, shade and solar radiation [3]. Shading can be classified into two main types: full shade and partial shade. Shading, whether partially or completely is due to neighboring buildings, clouds, towers, or trees [4], and even from dirt on the panel's cells, such as dust or birds' droppings [5]. The effect of shading on the performance of the PV array is important because it affects significantly on the system efficiency [6]. Several researchers have studied the properties of PV arrays and the influence of various designs and operational factors [5], [7], [8]. The shade that is formed on the solar panel is considered one of the most affecting factors that is taken into consideration when building system operating on the solar cells. Because of the fact that the shade has an influence on the ability of the solar radiation falling on the panel. As a result, this leads to a 
decrease in the electrical power output and this capacity is affected by the size and shape of the shade formed on the surface of the solar panel. Moreover, shade can cause a hot spot on the panel that could damage the panel. Shading simulation model for PV modules was created by Yunlin Sun et. al. [9] as a result of the investigation of a 20 MW grid connected PV plant in northwestern China. Typical shading phenomena classified and analysed individually, such as energy shading of distribution buildings and wire poles, plant, bird droppings, and shadow from front row. A series of experiments were conducted to evaluate and compare the presence of shadow effect and proposals were made to avoid or reduce the shading effect of the PV system during operation in this area [3]. Al-chaderchi et. al. [10] carried out several experiments to study the phenomenon of the total shade effect on photovoltaic panels equipped with the same manufacturer, but with power different number of diodes. From the study of the $\mathrm{C}-\mathrm{V}$ characteristics of all cases, they noted that the bypass diodes will reduce the effect of shade and have better performance in the case for three bypass diodes [11]. Galeano et. al. [12] studied a simplified modeling by using shade ratio and analyzing performance of partially shaded photovoltaic panels. REERC building PV system is a replacement of an old solar absorption system. The old system contains maintenance bridges, since the shadow of these bridges has no effect on the absorption system performance. The system was later on upgraded into $155 \mathrm{~kW}$ PV system, where maintenance bridges could have significant influence on the performance of the system. However, this influence was not investigated or taken into account during the design or installation.

In this paper, the effect of partial shade resulting from maintenance bridges fixed on the PV system of REERC building is investigated to evaluate the loss in the PV system productivity due to these bridges.

\section{Experimental Work}

Monocrystalline silicon PV panel of $\sim 288 \mathrm{~W}$ STC rated power was used in this study. The panel comprises of $96 \mathrm{p}-\mathrm{n}$ junction rectangular cells connected on series to provide around $\sim 48 \mathrm{~V}$ open circuit voltage with a total area of $2 \mathrm{~m}^{2}$. Parts of the panel were shaded to mimic the maintenance bridge frame effect on the PV system of REERC building. Shade area was chosen to imitate the actual shade as close as possible. Shades areas and locations were already determined at three different times (08:30AM, 10:00Am, and 12:00PM) and nine various months (January through September). It is worthy to note that three months have been missed due to the pandemic lockdown. All measurements were carried out using PV Analyser (Type Solar-4000). Shade area for each month was imitated and denoted as S0 to 9 and defined in Table (1), where S0 represents the no shaded reference panel and S9 represents the highest shaded panel. Each measurement was preceded by a "no shade" measurement to reference the results. Figures $(1-3)$ are photographs for each case in the study.

Table 1. Nomenclature of the shades cases.

\section{8:30 AM (Illustrated in Figure 1)}

S0: Without shade.

S1: Shade area $3 \mathrm{~cm}^{2}$ covering part of the last raw of the panel starting from the bottom edge.

S2: Shade area $4 \mathrm{~cm}^{2}$ covers the last part of the panel $2 \mathrm{~cm}$ from the bottom edge

S3: Shade area of $6 \mathrm{~cm}^{2}$ covers the top of the panel.

S4: Shade area of $7 \mathrm{~cm}^{2}$ covers the top of the panel.

S5: Shade area $7 \mathrm{~cm}^{2}$ down by $5 \mathrm{~cm}$ starting from $5 \mathrm{~cm}$ from the upper edge.

S6: Shade area $7 \mathrm{~cm}^{2}$ down by $4 \mathrm{~cm}$ starting from $5 \mathrm{~cm}$ from the upper edge.

S7: Shade area $8 \mathrm{~cm}^{2}$ covers the top of the panel.

S8: Shade area $8 \mathrm{~cm}^{2}$ down by $4 \mathrm{~cm}$ starting from $5 \mathrm{~cm}$ from the upper edge.

S9: Shade area $10 \mathrm{~cm}^{2}$ down by $2 \mathrm{~cm}$ starting from $5 \mathrm{~cm}$ from the upper edge.

10 AM (Illustrated in Figure 2) 
S0: Without shade.

S1: Shade area $1 \mathrm{~cm}^{2}$ covering part of the last raw of the panel starting zero from the bottom edge. S2: Shade area $3 \mathrm{~cm}^{2}$ covering part of the last raw of the panel starting zero from the bottom edge. S3: Shade area of $3 \mathrm{~cm}^{2}$ covers the centre of the panel.

S4: Shade area of $7 \mathrm{~cm}^{2}$ covers the centre of the panel.

S5: Shade area of $8 \mathrm{~cm}^{2}$ covers the centre of the panel.

S6: Shade area of $10 \mathrm{~cm}^{2}$ covers the centre of the panel.

S7: Shade area of $10 \mathrm{~cm}^{2}$ covers the top of the panel

\section{PM (Illustrated in Figure 3)}

S0: Without shade.

S1: Shade area $3 \mathrm{~cm}^{2}$ down by $8 \mathrm{~cm}$ starting from $5 \mathrm{~cm}$ from the upper edge.

S2: Shade area of $4 \mathrm{~cm}^{2}$ covers the centre of the panel.

S3: Shade area $4 \mathrm{~cm}^{2}$ covering part of the last raw of the panel starting zero from the bottom edge.

S4: Shade area $5 \mathrm{~cm}^{2}$ covers the last part of the panel starting $2 \mathrm{~cm}$ from the bottom edge.

S5: Shade area $6 \mathrm{~cm}^{2}$ covers the last part of the panel starting $4 \mathrm{~cm}$ from the bottom edge.

S6: Shade area $7 \mathrm{~cm}^{2}$ covers the last part of the panel starting $2 \mathrm{~cm}$ from the bottom edge.

S7: Shade area $7 \mathrm{~cm}^{2}$ covers the last part of the panel starting $4 \mathrm{~cm}$ from the bottom edge.

S8: Shade area $8 \mathrm{~cm}^{2}$ down by $5 \mathrm{~cm}$ starting $5 \mathrm{~cm}$ from the upper edge.

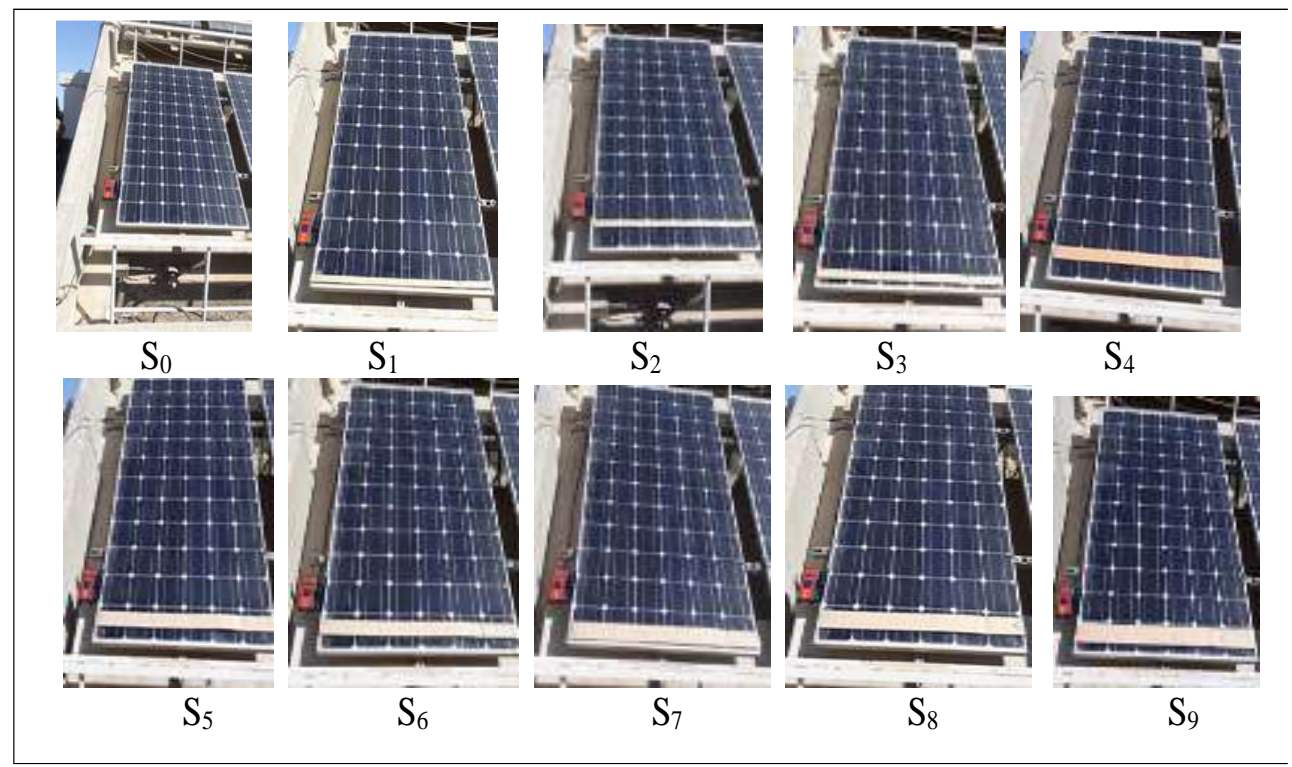

Figure 1. Photos of the shade at 8:30 AM. 


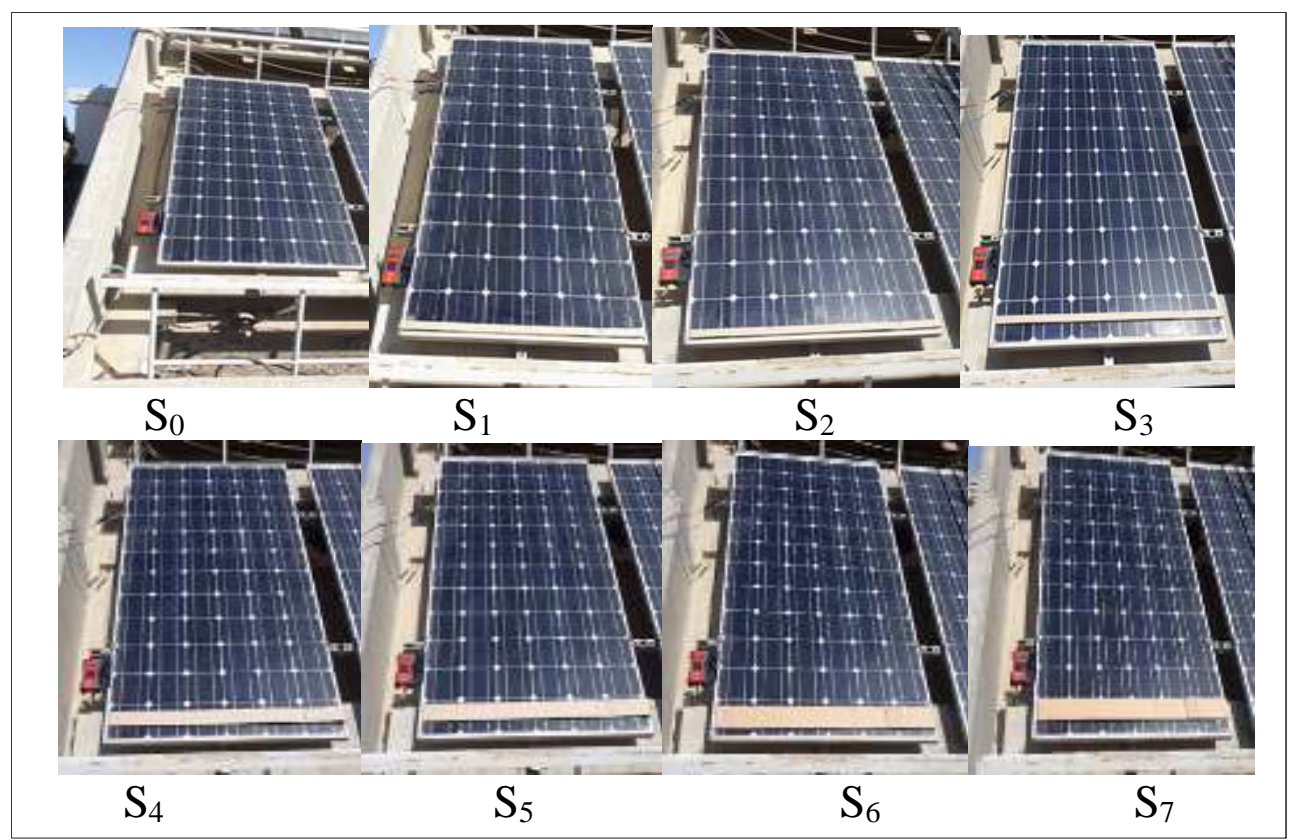

Figure 2. Photos of the shade at 10 AM.

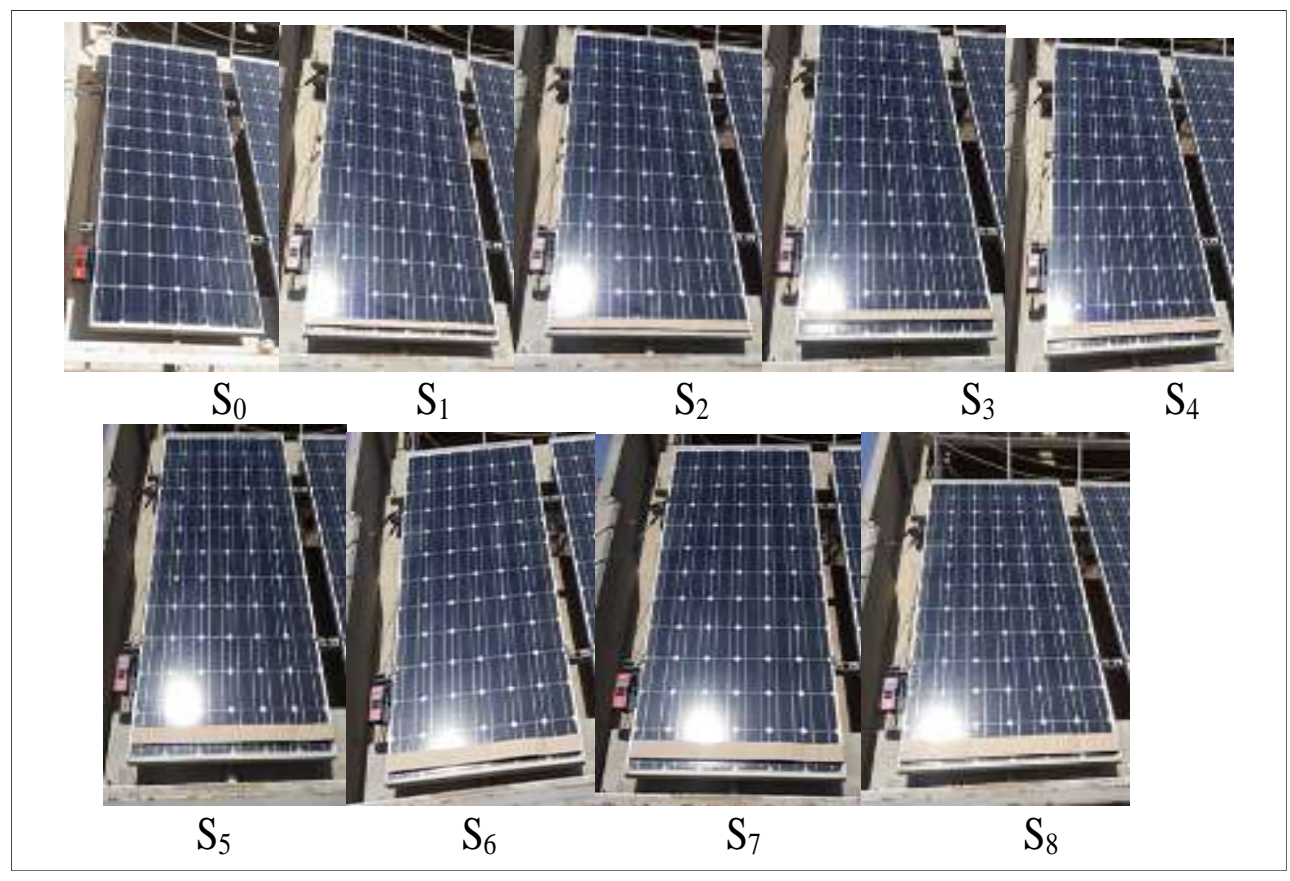

Figure 3. Photos of the shade at 12 PM.

\section{Results and Discussion}

The IV characteristics of the panel at various measurement times and shades are shown in figure (4). The figure shows that the photocurrent decreases with the existence of partial shade compared with the no shade case. In addition, the photocurrent increases with time and shows highest values at 12 PM. This is certainly, due to sun illumination that gets higher at noon compared to early morning. 


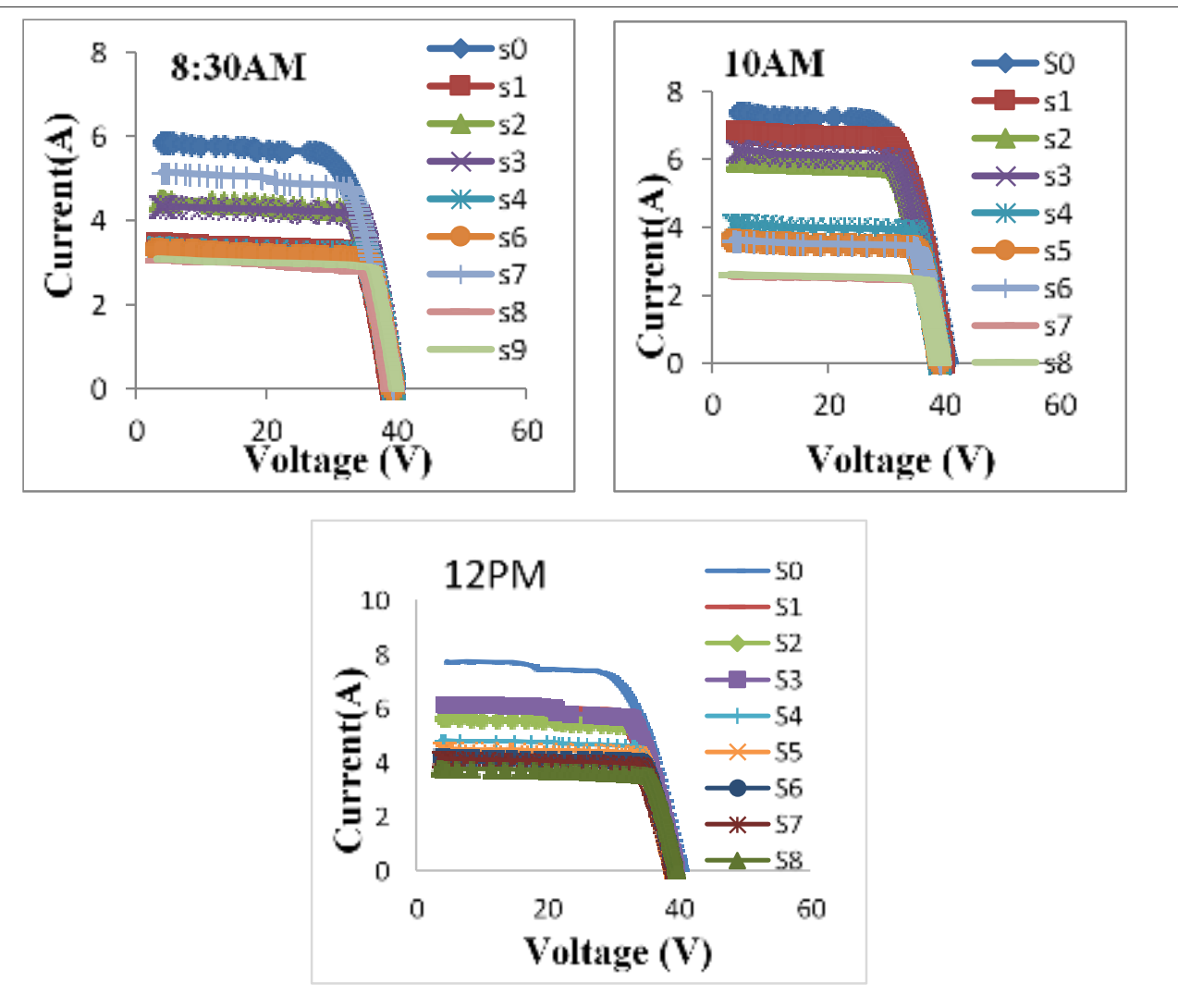

Figure 4: I-V Characteristics of solar panel at various times and shades.

Radiation density (so called irradiance) versus shade location $\left(S_{X}\right)$ is illustrated in figure (5). Irradiance shows an average of $700 \mathrm{~W} / \mathrm{m}^{2}$ at $8: 30 \mathrm{AM}, 850 \mathrm{~W} / \mathrm{m}^{2}$ at $10 \mathrm{AM}$, and $950 \mathrm{~W} / \mathrm{m}^{2}$ at noon with a slight variation over the span of 9 months. 


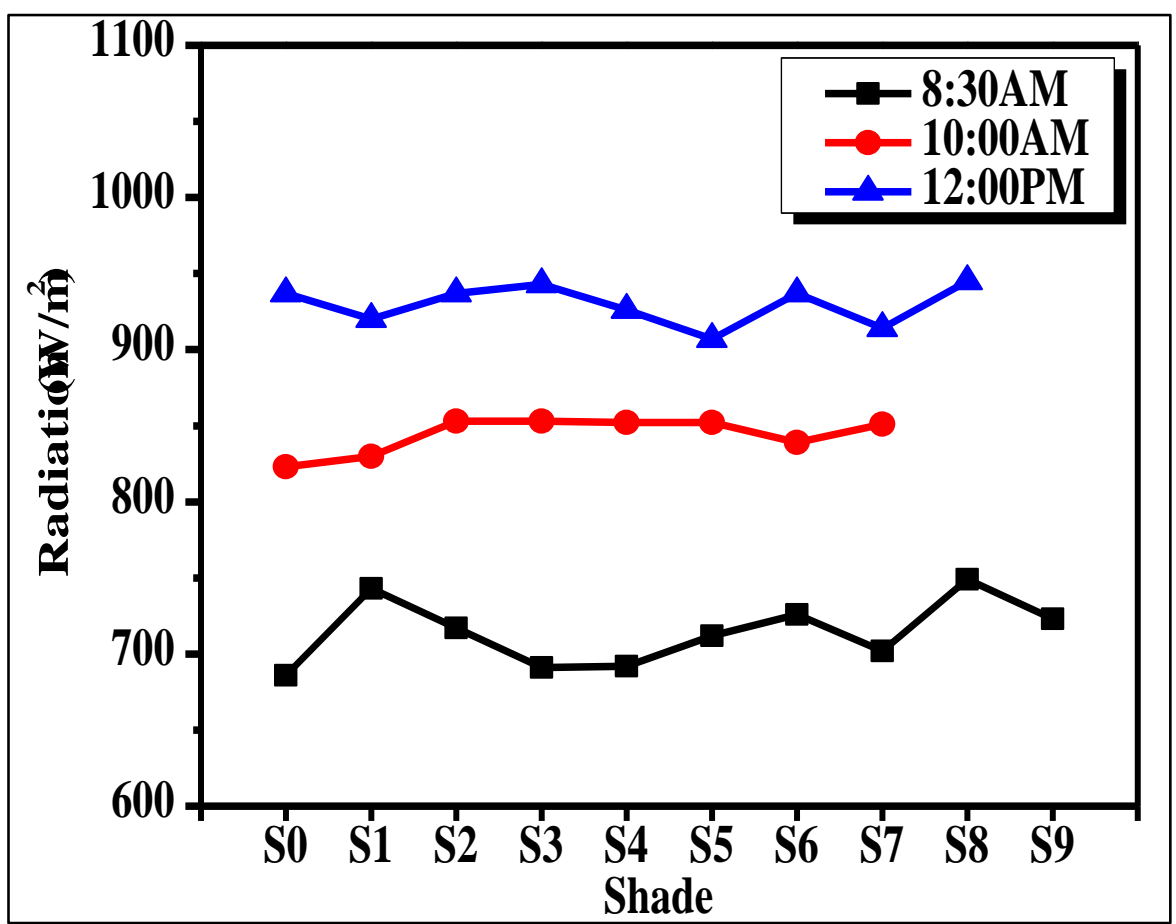

Figure (5): Radiation density variation with partial shade location.

Figure (6) demonstrates the variation of PV panel parameters with partial shade area and location. The shade area $S_{X}$ is numbered in order so that S1 is the smallest shade area while S9 is the largest shade area. Im and Isc in figure (6) exhibit a steep decrease with shade area, whereas, Vm and Voc exhibit a slight decrease with shade area. Therefore, both Pm and PCE decrease sharply with shade area. To explain the variation of photocurrent and photovoltage with shading area, Eqs. $(1 \& 2)$ are utilized. The relationship between Isc and radiation [10] is:

$\mathrm{Isc}=\mathrm{K}_{\mathrm{R}} * \mathrm{R}$

Where $\mathrm{R}$ is the radiation density, $\mathrm{K}_{\mathrm{R}}$ is a constant that characterizes the relative variation of short circuit current as a function of irradiation. The $K_{R}$ value for monocrystalline silicon panel is $0.0037 \mathrm{~A} \cdot \mathrm{m}^{2} / \mathrm{W}$ [12] and is $0.0025 \mathrm{~A} . \mathrm{m}^{2} / \mathrm{W}$ for CIGS technology under the same conditions. The open circuit voltage as a function of irradiation is described as:

$$
V o c=V o c n+\frac{n K T}{q} \ln R / R n
$$

Where Voc and $R_{n}$ are the open circuit voltage and the irradiation under nominal conditions. As irradiance increases, Voc increases linearly as described in Eq. (2). However, as irradiance increases, the logarithm value is too small which reflects only a slight change in Voc. Hence, Voc shows insignificant change with irradiance [13].

Loss in power, voltage, and current are illustrated in Figure (7). The figure shows a small loss in voltage (less than $3 \%$ ), while the loss in current, and hence in power is almost 50\% in some shade areas, which is dramatically significant. 


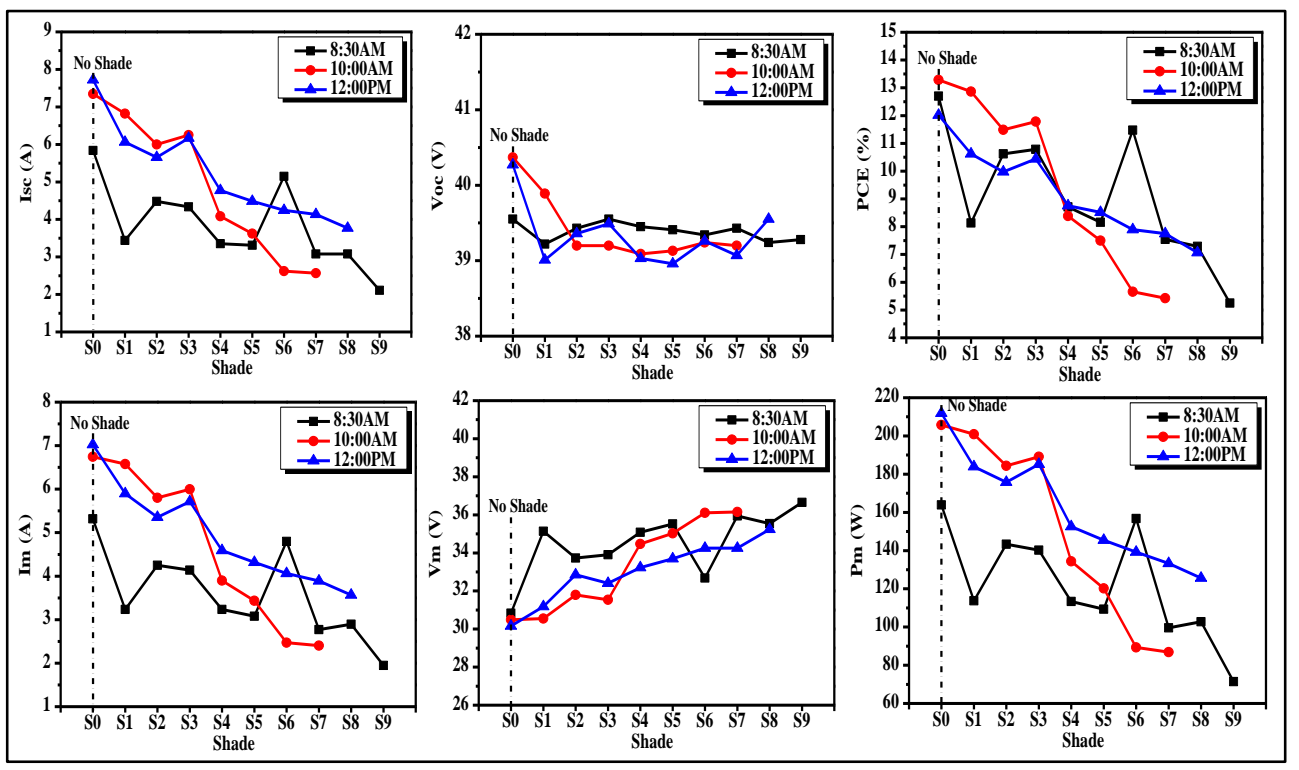

Figure 6. PV panel parameters ( $\mathrm{I}_{\mathrm{SC}}, \mathrm{V}_{\mathrm{OC}}, \mathrm{PCE}, \mathrm{Im}, \mathrm{Vm}$, and $\mathrm{Pm}$ ) at 8:30AM, 10:00AM, and 12:00PM measurements times.

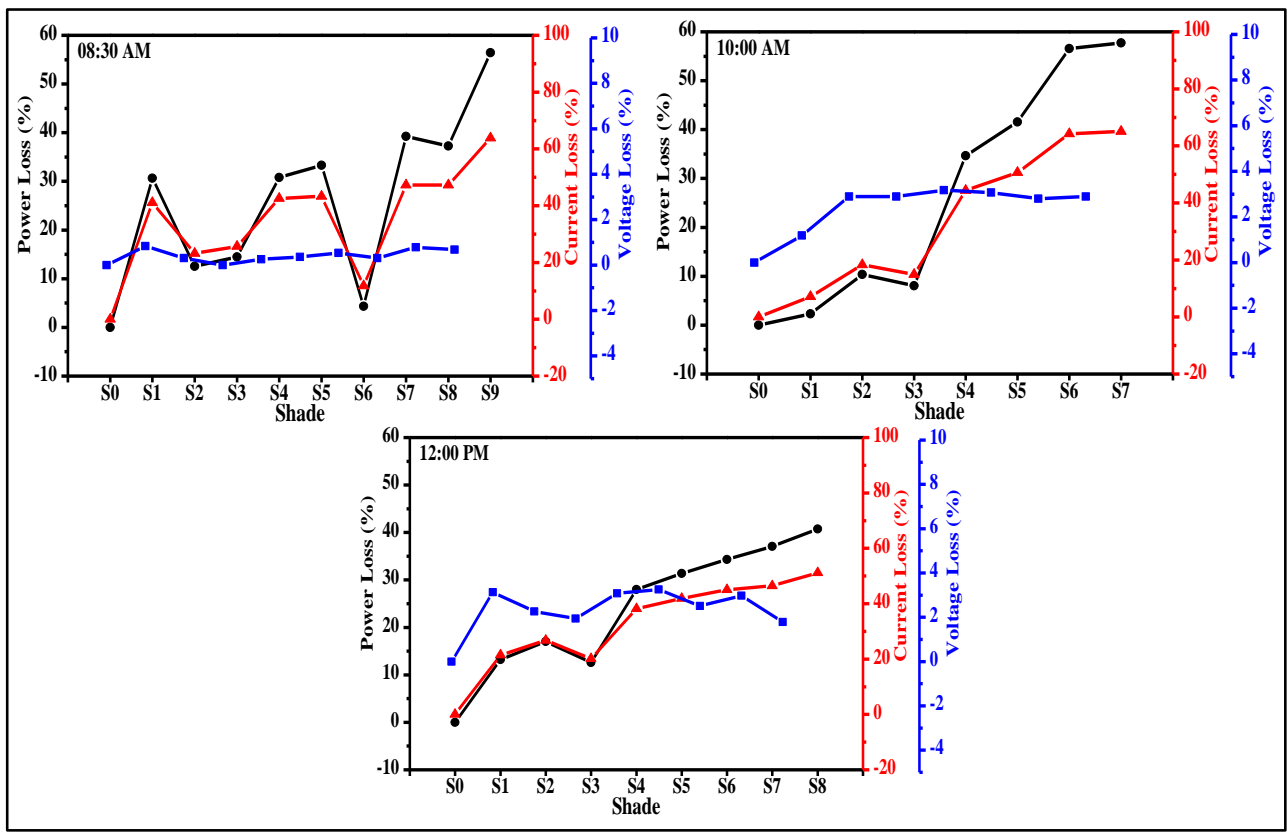

Figure 7. PV panel loss in Pm, Vm, and Im due to partial shade at 8:30AM,10:00AM, and 12:00PM.

It is well-known that ambient temperature is a major suppressor for PV panel productivity, and it is also known that panel's temperature is significantly higher than ambient temperature because PV panel surface is a perfect black colored absorber. The passing photocurrent also contributes in heating. Figure (8) shows the effect of ambient temperature on the productivity of a $230 \mathrm{~W}$ PV panel. 


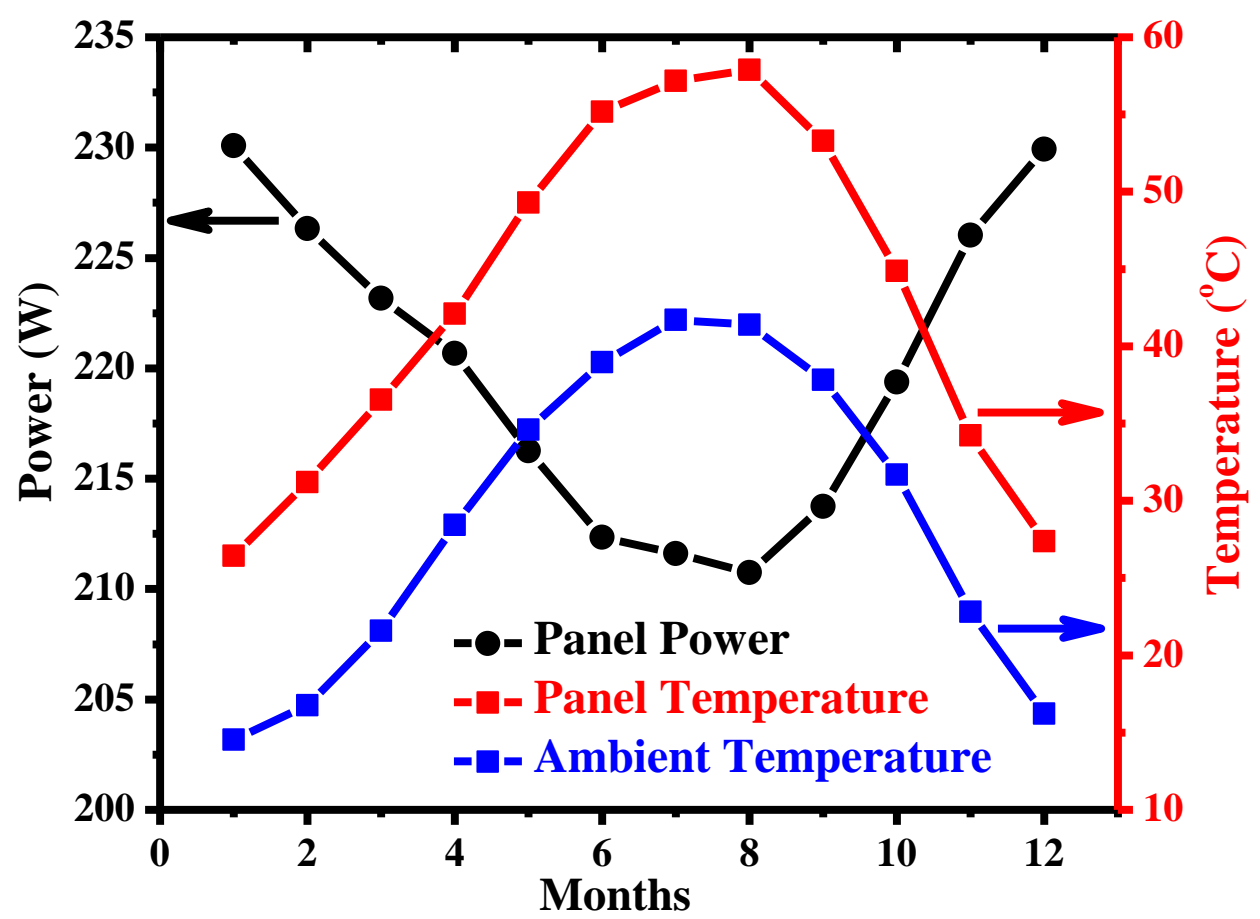

Figure 8. Temperature effect on the PV rated power.

To calculate PV panel's surface temperature at a certain ambient temperature, we can use Homer method [14]. In this method, two factors have to be calculated for a particular panel (A \& B):

$\mathrm{A}=(\mathrm{NOCT}-20) / \mathrm{R}$

$\mathrm{B}=1-(\mathrm{PCE} / 0.9)$

Where NOCT: panel's operating temperature $\left(50{ }^{\circ} \mathrm{C}\right.$ in our panels), 20: the ideal pn junction temperature, R: the measured solar radiation, PCE: the power conversion efficiency of the panel, and 0.9: a constant. If the radiation is $0.8 \mathrm{~kW} / \mathrm{m}^{2}$ and PCE is $13 \%$, for an example, then factor $\mathrm{A}=(50-20) / 0.8=37.5$, and factor $\mathrm{B}=1-(0.13 / 0.9)=$ 0.85. The PV panel's surface temperature is [15]:

Panel Temp. $(\mathrm{T})=$ Ambient Temp $+($ Radiation $\times \mathrm{A} \times \mathrm{B})$

$\mathrm{T}=50+(0.8 \times 37.5 \times 0.85)=89.15^{\circ} \mathrm{C}$

The PV power drop due to PV surface temperature is calculated from the following equation [16]:

Power Drop $=(T-25) \times$ Temp. Coef.

Where Temp. Coef.: temperature coefficient of the PV panel determined by the manufacturer $\left(-0.5 \% /{ }^{\circ} \mathrm{C}\right)$, T: the PV panel's surface temperature, and 25: room temperature. 
Hence: Power drop $=(89.15-25) \times\left(-0.5 \% /{ }^{\circ} \mathrm{C}\right)=-32 \%$.

For a PV panel of $288 \mathrm{~W}$ power, the actual power at $50^{\circ} \mathrm{C}$ ambient temperature will be $196 \mathrm{~W}$. Therefore, for a PV system comprising of 540 panel, the power will drop from $155 \mathrm{~kW}$ to $106 \mathrm{~kW}$.

The PV system of REERC building consists of $540 \mathrm{PV}$ panel of $288 \mathrm{~W}$ average power each. The designed power capacity of the system is $155 \mathrm{~kW}$. The actual maximum power measured directly from the system at noon in a chosen day (March 9, 2020) was 78kW as show in figure (9).

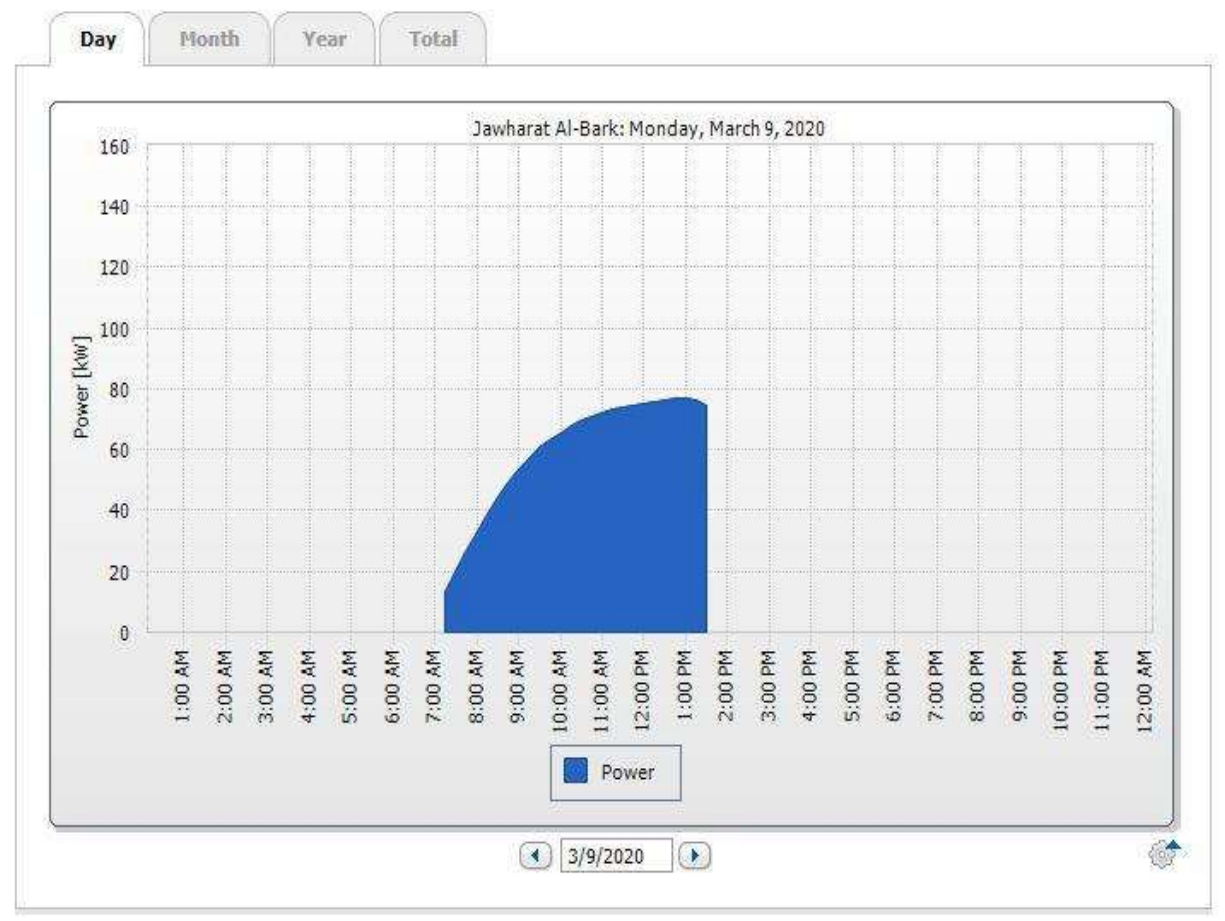

Figure 9. Actual yield of PV system in REERC building.

To estimate the effect of maintenance bridges shade on the REERC PV system, one PV panel was intentionally shaded with the same pattern of the maintenance bridge shade as described elsewhere. The results of the panel were projected to the whole system to estimate the loss of the total REERC system (540 PV panel). As illustrated in figure (10), the designed power is $155 \mathrm{~kW}$. The calculated power due to ambient temperature using Homer method is $106 \mathrm{~kW}$, and this is a $31 \%$ drop in power. The output power for shaded panels (with eliminating the temperature effect) after extrapolating one panel to 540 panels projection at noon in sunny day at March (dated 9/3/2020) is 100kW with a drop of $35 \%$. This result is higher than the effect of temperature, even when the shading area is no more than $2 \%$ of the total panel's area. The actual rated power is $78 \mathrm{~kW}$ at noon in March 9, 2020. This is a drop of 50\% of the power. This huge drop is a combined effect for both shade and ambient temperature. 


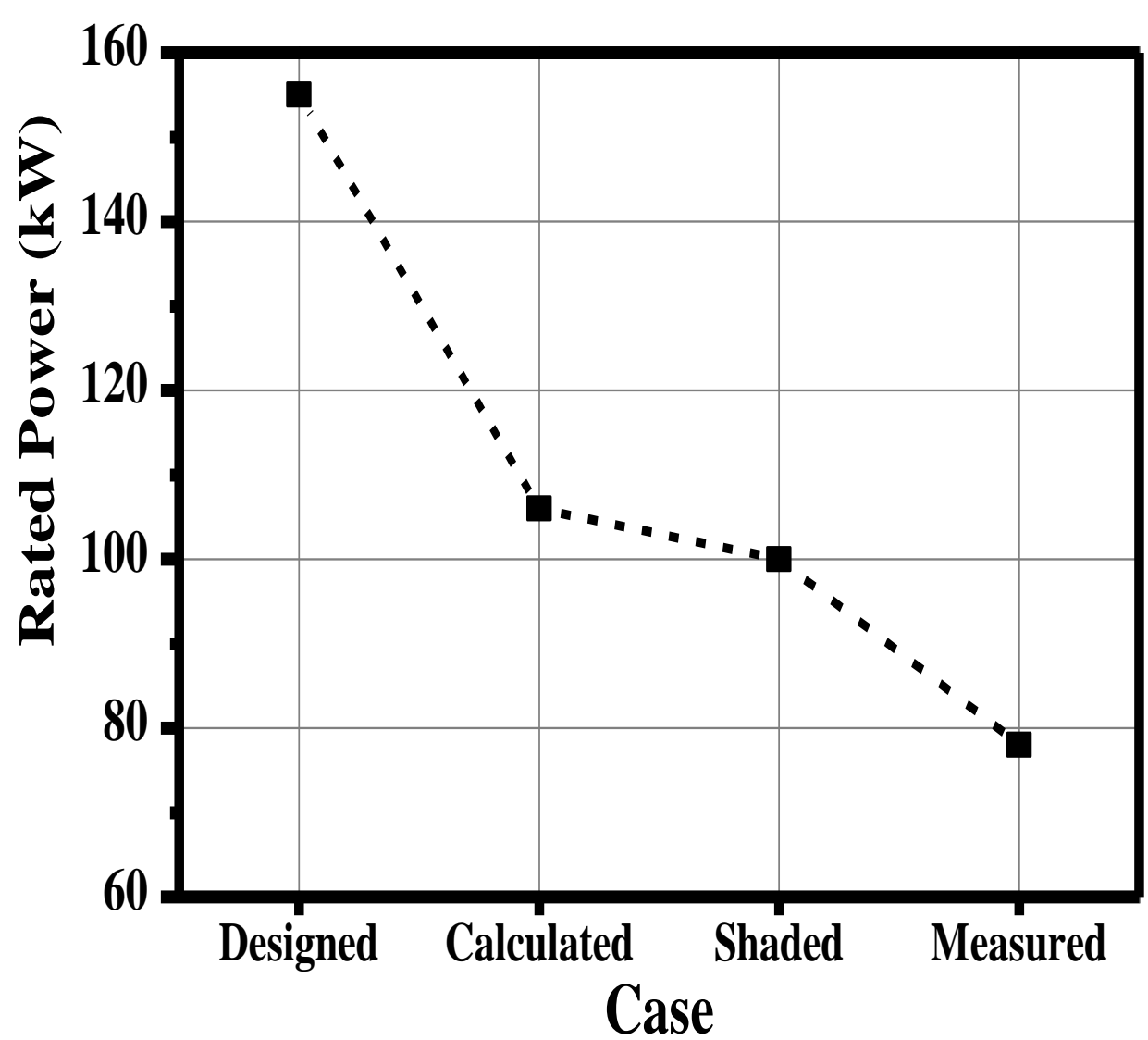

Figure (10). Effect of shade on the productivity of REERC PV system.

\section{Conclusions}

From what has been discussed earlier, it can be concluded that partially shaded PV panels loses a noticeable amount of their productivity (around 35\% with partially shaded area of 2\%). Considering the effect of temperature, especially in hot countries such as Iraq, the loss of the PV productivity can reach up to 50\%. Since hot weather cannot be controlled because it is related to the location, PV designers should take into account seriously the shade effect even partial shade (2\%). In the case of REERC PV system, the building was already designed for solar absorbers where maintenance bridges have no effect on it. When the PV system was supplanted, the PV panels were installed on the same infrastructure, so that designers could not avoid the bridges.

\section{Acknowledgment}

Financial and logistic support from the Renewable Energy and Environment Research Center (REERC) at the Corporation of Research and Industrial Development is greatly appreciated.

\section{References}

[1] R. Yan, T. K. Saha, P. Meredith, and S. Goodwin, "Analysis of yearlong performance of differently tilted photovoltaic systems in Brisbane, Australia,” Energy Convers. Manag., vol. 74, pp. 102-108, 2013.

[2] A. A. Al-Kayssi, O. A. Abdulrazzaq, and N. T. Hamad, "Analyzing of Global Solar Radiation over Baghdad," 
Int. J. Sci. Res., vol. 7, no. 9, pp. 306-308, 2018.

[3] S. P., R. Ballal, L. S. P. S., and G. Kumar, "Effect of Shading on the Performance of Solar PV Panel," Energy and Power, vol. 5, no. 1A, pp. 1-4, 2015.

[4] I. H. Mahammed et al., "Outdoor study of partial shading effects on different PV modules technologies," Energy Procedia, vol. 141, pp. 81-85, 2017.

[5] O. A. Abdulrazzaq, A. Abdullah, S. K. Abdulridha, and M. A. Fakhri, "Dirt-proof Silicon PV Panel Surface using Superhydrophobic Nano-composite," Iraqi J. Ind. Res., vol. 5, no. 2, pp. 1-8, 2018.

[6] E. Koutroulis and F. Blaabjerg, "A New Technique for Tracking the Global Maximum Power Point of PV Arrays Operating Under Partial-Shading Conditions," IEEE J. Photovoltaics, vol. 2, no. 2, pp. 184-190, 2012.

[7] A. Salloom, O. Abdulrazzaq, and B. Ismail, "Assessment of the Performance of Bifacial Solar Panels," Int. J. Eng. Tech. Res., vol. 8, no. 7, pp. 13-17, 2018.

[8] A. H. Salloom, O. A. Abdulrazzaq, B. H. Ismail, and A. D. Salman, "Ground Effect on the Performance of Back-to-back Stacked Silicon Solar Panel System: An Imitation for a Bifacial Solar Panel,” Iraqi J. Ind. Res., vol. 6, no. 1, pp. 8-15, 2019.

[9] Y. Sun, S. Chen, L. Xie, R. Hong, and H. Shen, "Investigating the Impact of Shading Effect on the Characteristics of a Large-Scale Grid-Connected PV Power Plant in Northwest China," Int. J. Photoenergy, vol. 2014, p. 763106, 2014.

[10] M. Al-Chaderchi, K. Sopain, M. A. Alghoul, and T. Salameh, "Experimental study of the effect of fully shading on the Solar PV module performance," E3S Web Conf., vol. 23, 2017.

[11] E. . 1Ekpenyong and F. . 2Anyasi, "Effect of Shading on Photovoltaic Cell," IOSR J. Electr. Electron. Eng., vol. 8, no. 2, pp. 01-06, 2013.

[12] A. G. Galeano, M. Bressan, F. J. Vargas, and C. Alonso, "Shading ratio impact on photovoltaic modules and correlation with shading patterns," Energies, vol. 11, no. 4, pp. 1-26, 2018.

[13] M. Chegaar, A. Hamzaoui, A. Namoda, P. Petit, M. Aillerie, and A. Herguth, "Effect of illumination intensity on solar cells parameters," Energy Procedia, vol. 36, pp. 722-729, 2013.

[14] T. A. Olukan and M. Emziane, "A comparative analysis of PV module temperature models," Energy Procedia, vol. 62, pp. 694-703, 2014.

[15] J. Lu, W. Wang, Y. Zhang, and S. Cheng, "Multi-objective optimal design of stand-alone hybrid energy system using entropy weight method based on HOMER," Energies, vol. 10, no. 10, 2017.

[16] J. K. Kaldellis, M. Kapsali, and K. A. Kavadias, "Temperature and wind speed impact on the efficiency of PV installations. Experience obtained from outdoor measurements in Greece," Renew. Energy, vol. 66, no. May 2016, pp. 612-624, 2014. 